\title{
SABERES E PRÁTICAS DA ESCOLARIZAÇÃO DO ALUNO COM SURDEZ NO ENSINO REGULAR: (RE)CONSTRUÇÕES NECESSÁRIAS
}

\author{
KNOWLEDGE AND PRACTICES OF EDUCATION OFSTUDENTS WITH \\ DEAFNESS ON REGULAR EDUCATION: CONSTRUCTION NEEDED
}

\author{
FERNANDES, Carla Helena \\ carlahelenafernandes@yahoo.com.br \\ UNIVÁS - Universidade do Vale do Sapucaí \\ CAMPOS, Aline Rezende \\ alinerc_minas@hotmail.com \\ UNIVÁS - Universidade do Vale do Sapucaí
}

\begin{abstract}
RESUMO A inclusão de alunos com necessidades educacionais especiais no ensino regular tem exigido reconstruções na organização dos sistemas de ensino e escolas. A pesquisa apresentada, um estudo de caso, resgata e analisa o processo de escolarização na Educação Básica de uma aluna com surdez. Para tal investigação foram realizadas entrevistas semiestruturadas com a própria aluna, familiares e profissionais das escolas. Os resultados indicaram, por um lado, aspectos que representaram barreiras ao desenvolvimento da aluna, como a ausência da Língua Brasileira de Sinais e, por outro, práticas, como o trabalho entre os pares de estudantes, que foram fundamentais para sua aprendizagem. Porém, nessa análise deve também ser considerada a necessidade de planejamento dessas práticas, em especial quanto à participação e mediação do professor. Os resultados dessa investigação contribuem com reflexões sobre a escolarização de alunos com necessidades educacionais especiais e com observações acerca da organização de ambientes inclusivos: escolas e salas de aula.
\end{abstract}

PALAVRAS-CHAVE: Formação docente. Inclusão escolar. Trabalho colaborativo.

ABSTRACT The inclusion of students with special educational needs in mainstream education has required reconstruction in the organization of education systems and schools. The research presented a case study, recovers and analyzes the process of schooling Basic Education of a student with deafness. For this research, were conducted semi-structured interviews with his own student, family and school professionals were conducted. The results indicated, firstly, aspects that represented barriers to the development of the student, as the absence of Brazilian Sign Language, and secondly, practices, such as work between pairs of students that were fundamental to their learning. However, this analysis, should be considered the need planning of these practices, especially with regard to participation and teacher mediation. The results of this research contributes to reflections on the education of students with special educational needs and observations about organizing inclusive environments: schools and classrooms.

KEYWORDS: Collaborative work. School inclusion. Teacher education. 


\section{INTRODUÇÃO}

A inclusão de alunos com necessidades educacionais especiais ${ }^{1}$ no ensino regular ganhou força a partir da década de 90 do século XX e ainda tem exigido reflexões e mudanças nas práticas pedagógicas e na organização dos sistemas de ensino e escolas visando à garantia do acesso, permanência e aprendizado desses alunos respeitando-se suas singularidades, oferecendo educação de qualidade a todos.

A história, a legislação e os documentos oficiais para a área, entre esses a Declaração de Salamanca (UNESCO, 1994), afirmam que a conquista do direito à educação tem sido construída pela sociedade, profissionais da Educação e também pelas pessoas com necessidades educacionais especiais, buscando-se a garantia do direito de frequentarem a escola de ensino regular. Entretanto, mesmo diante dos grandes avanços, vemos que essa é ainda uma construção e, para sua realização, faz-se necessário que se tracem metas coletivas, inseridas ao projeto pedagógico das escolas, e com a participação da família, envolvendo ações dirigidas à sala de aula e à escola como um todo, visto que a inclusão escolar de alunos com necessidades educacionais especiais implica em um processo educacional relacionado não somente a competências acadêmicas, mas também à construção da autonomia e cidadania. Especificamente em relação à escolarização de alunos com surdez, seu processo de escolarização deve alicerçar-se em práticas que possibilitem a efetiva participação desse aluno no ambiente escolar e na sociedade.

Visando à construção da inclusão escolar, compreendemos que o resgate e a reflexão sobre a escolarização de alunos com necessidades educacionais especiais podem contribuir nas mudanças que se fazem necessárias. Nesse sentido, a pesquisa desenvolvida objetivou investigar e refletir sobre práticas pedagógicas desenvolvidas nesse processo, tendo como referência estudo de caso sobre a escolarização de uma aluna com surdez na Educação Básica. $O$ texto que segue

\footnotetext{
${ }^{1}$ Neste texto se fez uso da expressão "alunos com necessidades educacionais especiais" para indicar alunos com deficiências (sensorial [cegueira e surdez], física e intelectual), transtorno global do desenvolvimento e superdotação/altas habilidades, como indica o documento "Política Nacional de Educação Especial na Perspectiva da Educação Inclusiva" (MEC, 2008).
} 
apresenta alguns aspectos dessa pesquisa, bem como uma discussão acerca da inclusão escolar.

\section{SOBRE A ESCOLARIZAÇÃO DO ALUNO COM SURDEZ}

Visando à efetiva inclusão escolar de alunos com necessidades educacionais especiais, faz-se necessário que não se restrinja a inclusão escolar desse aluno a sua matrícula no ensino regular, mas também que se possibilitem às escolas e seus profissionais meios necessários a essa construção. Nesse sentido, um dos principais aspectos a ser pensado em relação à escolarização do aluno com surdez é a necessidade de ambientes efetivamente inclusivos que visem a seu desenvolvimento e aprendizagem. Esses ambientes devem privilegiar práticas e recursos que atendam às necessidades pedagógicas do aluno, o que deve ser identificado e organizado também a partir de sua participação nesse processo. Skliar (2009) diz da necessária implicação do aluno com surdez na reconstrução da educação escolar.

\footnotetext{
Estarei falando, então, do conceito de uma educação e de uma escola possível? Sim e não. Se, por educação e por escola possível, entende-se uma utopia, uma promessa dos ouvintes de libertação dos surdos, não é esse o sentido da minha representação sobre o 'possível'. O sentido que dou a uma educação e a uma escola possivel se refere à criação de políticas linguísticas, de identidades, comunitárias e culturais, pensadas a partir do que os outros, os surdos, se representam como possível e do modo como os outros, os surdos, reconstroem o próprio processo de educação. (SKLIAR, 2009, p. 26)
}

Construir a educação inclusiva nas escolas de ensino regular implica, de forma ampla, na consideração de outro paradigma cuja base é o direito do aluno e cidadão surdo. De forma específica, refere-se à viabilização deste direito por meio de práticas pedagógicas que considerem as características e especificidades desse aluno.

As práticas pedagógicas podem ser definidas como um conjunto de ações que se realizam tendo um fim e que exigem, para que assumam caráter pedagógico, organização e reflexão. Embora tenham como espaço-tempo a sala de aula e, como sujeitos envolvidos, professores e alunos, envolvem também dimensões mais 
amplas, da escola e do currículo, bem como promovem a entrada em cena de outros sujeitos. De acordo com Franco (2012, p. 173), as práticas pedagógicas "se organizam intencionalmente para atender a determinadas expectativas educacionais solicitadas/requeridas por uma dada comunidade social"; além disso, continua a autora, "se organizam e se desenvolvem por adesão, por negociação ou, ainda, por imposição" (FRANCO, 2012, p. 174).

Assim, quando dizemos de práticas pedagógicas voltadas ao aprendizado de alunos com necessidades educacionais especiais, propomos, a partir das ideias dos autores, que sejam localizadas no interior de um processo de construção. Referimos-nos ao trabalho pedagógico que cotidianamente os profissionais da educação têm construído, com o apoio de familiares, em ações através das quais se reconstrói a educação visando à inclusão escolar.

Nessa construção há, porém, outro aspecto que precisa ser efetivamente considerado: o que sabe o professor, fruto dos cursos de formação inicial e da experiência anterior, é reconstruído no cotidiano escolar e no exercício da docência. Tardif (2007) afirma que toda prática integra diferentes saberes com os quais os sujeitos têm diferentes relações, podendo, assim, definir os saberes como "saber plural, formado pelo amálgama, mais ou menos coerente, de saberes oriundos da formação profissional e de saberes disciplinares, curriculares e experienciais" (TARDIF, 2007, p. 36). Se os três primeiros - saberes da formação profissional, disciplinares e curriculares - são produzidos pelas ciências da educação, transformados em programas curriculares e transmitidos pelos organismos formadores, os saberes experienciais são aqueles produzidos pelos professores a partir de seu próprio trabalho e caracterizam-se pelo fato de se originarem da prática cotidiana da profissão. Nessa perspectiva, os saberes que subjazem às práticas podem ser via de mão dupla, transformados por elas, ressignificados no cotidiano do trabalho docente a partir do novo que atravessando o conhecimento dos professores está presente em cada aluno que adentra a escola provocando outras situações e acontecimentos.

Em relação ao atendimento pedagógico, em sala de aula, de alunos com necessidades educacionais especiais, os saberes do curso da formação inicial de professores são alargados com a entrada de novos saberes e com a participação 
dos saberes de outros sujeitos - em especial, de outros profissionais -, com quem o professor da classe comum dialoga. Esse alargamento poderá, a princípio, provocar a intranquilidade da incerteza; aos poucos, porém, a nova aprendizagem terá seu lugar no contínuo ressignificar da experiência docente.

\section{O ENCAMINHAMENTO DA PESQUISA}

A pesquisa desenvolvida teve como objetivo resgatar e analisar o processo de escolarização, na Educação Básica, de uma aluna com surdez, visando identificar e analisar pontos frágeis, aspectos positivos e mudanças necessárias, como forma de contribuir com as reflexões acerca da inclusão escolar de alunos com necessidades educacionais especiais. A pesquisa foi desenvolvida em um município localizado ao sul do estado de Minas Gerais e, tendo como referência a abordagem qualitativa de pesquisa (LUDKE; ANDRÉ, 1986; BOGDAN; BIKLEN, 1994), optou pelo estudo de caso (YIN, 2005) como procedimento metodológico. Para o levantamento de dados foram empregadas entrevistas semiestruturadas ${ }^{2}$ com a aluna com surdez, familiares (sua mãe) e profissionais que atuaram no seu processo de escolarização, a saber, professores do Ensino Fundamental (anos iniciais e finais) e Ensino Médio e o diretor de uma das Escolas que a aluna frequentou. Todos os profissionais, à época da realização das entrevistas, atuavam em escolas das redes públicas (municipal e estadual) do referido município sul mineiro. Considerando a importância da família no processo de escolarização de seus filhos, a opção por entrevistar também um familiar se justificou pela relevância para a pesquisa das informações deste sujeito, no caso a mãe da aluna.

A aluna $^{3}$, cuja escolarização foi foco da investigação, cursou o último ano do Ensino Médio em 2012. No quadro de alunos com surdez inclusos no ensino regular

\footnotetext{
${ }^{2}$ Segundo Trivinõs (1987), as entrevistas semiestruturadas têm início por questionamentos gerais sobre o tema da investigação que são desdobrados em outros questionamentos. Por sua forma de encaminhamento, que tem como objetivo o estabelecimento de um espaço de diálogo e expressão do entrevistado com o entrevistador, as entrevistas semiestruturadas possibilitam, segundo este autor, a explicação e compreensão de fenômenos sociais em sua totalidade e a partir das ideias dos sujeitos envolvidos.

${ }^{3}$ Embora a mesma, no momento da realização da pesquisa (primeiro semestre de 2013), já tivesse concluído a Educação Básica, fez-se uso do termo "aluna" para designá-la em função do seu lugar de sujeito em relação à investigação e temática, a saber, o processo de escolarização de alunos com surdez.
} 
do município, a seleção de um/a aluno/a concluinte da Educação Básica se justificou em função de que a análise de sua escolarização poderia promover visualização desse processo. De forma ampla, tal análise poderia ser estendida à reflexão sobre a inclusão escolar de outros alunos com surdez, o que é também a proposta dos estudos de caso.

Essa forma de encaminhamento metodológico, segundo Lüdke e André (1986) e Yin (2005), objetiva descrever e analisar a complexidade de uma situação, enfatizando o contexto, o meio, os recursos materiais e os sujeitos; também definese por investigação local, possível de ser estendida a outros contextos (YIN, 2005). Além disso, por envolver em sua investigação e análise vários aspectos da situação estudada, o estudo de caso, conforme Yin (2005), pode propiciar maior visibilidade ao objeto de pesquisa. Nesse sentido e tendo em vista o objeto e os objetivos da pesquisa, o desenvolvimento desse procedimento de pesquisa mostrou-se adequado para o estabelecimento de relações entre a história particular da inclusão escolar da aluna e a história social e coletiva da educação escolar de outros alunos com surdez que, como ela, frequentam escolas de ensino regular.

Entendemos que a fala dos sujeitos entrevistados contribuiu para a reconstrução do processo de escolarização dessa aluna por sua disposição (dos sujeitos) temporal, espacial e pedagógica ao longo desse processo. Em muitos momentos das entrevistas emergiu uma voz coletiva na fala desses entrevistados que também disseram sobre práticas gerais, desenvolvidas por outros profissionais nas escolas onde atuavam.

\section{APRESENTAÇÃO DO ESTUDO DE CASO}

\subsection{APRESENTAÇÃO DA ALUNA, HISTÓRIA ESCOLAR E TEXTUALIZAÇÃO DA ENTREVISTA: APROXIMAÇÕES}

A surdez da aluna foi descoberta aos dois anos de idade e, segundo relato da mãe (dados da entrevista), foi decorrente de infecções repetitivas de ouvido ${ }^{4}$. A

\footnotetext{
${ }^{4}$ Não se teve acesso a laudos e relatórios médicos e/ou aos profissionais da área da saúde que atuaram com a aluna; os profissionais da escola também não tinham informações a esse respeito.
} 
criança passou a fazer uso do aparelho auditivo aos cinco anos de idade, tendo muita dificuldade em adaptar-se. Na ocasião, foi encaminhada para instituto especializado, onde foi avaliada quanto à perda auditiva e atendida por Fonoaudióloga e Otorrinolaringologista. Porém, também segundo relato da mãe, em função da demanda do serviço público, a família encontrou dificuldade para que o atendimento em Fonoaudiologia acontecesse com continuidade, o que, de acordo coma mãe da aluna, dificultou o desenvolvimento da comunicação em geral. A aluna não aprendeu e/ou não fez uso da LIBRAS, a Língua Brasileira de Sinais.

Sua escolarização iniciou em 1997, aos quatro anos de idade, em uma Escola Especial, permanecendo nessa instituição até o terceiro ano do Ensino Fundamental. Em todo o processo de escolarização, a aluna não teve LIBRAS (dado obtido com a própria aluna e sua mãe), havendo, na Escola Especial, incentivo para o desenvolvimento da oralidade ${ }^{5}$. A aluna também não teve atendimento educacional especializado (à época, sala de recursos). Em 2004, foi transferida para uma escola de ensino regular, onde cursou o $4^{\circ}$ ano do Ensino Fundamental, sendo retirada nesse ano; iniciou o $5^{\circ}$ ano em 2006. Segundo seus professores (dados das entrevistas), a dificuldade de comunicação e de aprendizagem esteve presente em toda a escolarização, o que se manteve até a conclusão do Ensino Médio em 2012.

Desde os primeiros contatos das pesquisadoras com a aluna, observaram-se dificuldades de comunicação e até mesmo de interação e, por isso, visando ao bom desenvolvimento da entrevista, as pesquisadoras seguiram o encaminhamento indicado pela própria aluna para o estabelecimento de contato, a saber: primeiro, apenas contato por telefone com familiares; depois, os primeiros contatos com a aluna através de recursos de internet (mensagem de e-mail e por meio de rede social indicada pela aluna); e, somente depois, marcou-se a entrevista, em data, local e horário estipulados pela entrevistada. Na entrevista, seguiu-se o mesmo roteiro usado com os demais sujeitos. Durante a entrevista, a aluna, que é oralizada, fez uso de frases curtas e palavras isoladas. As dificuldades de comunicação e

\footnotetext{
${ }^{5} \mathrm{Na}$ história da inclusão social e escolar da pessoa com surdez, um dos primeiros períodos caracterizou-se pela abordagem oralista, ou seja, havia estímulo e, em alguns casos, imposição, para que essas pessoas se comunicassem através da fala e/ou da leitura labial (DIAS; SILVA; BRAUN, 2009). Porém, atualmente, defende-se o bilinguismo com a adoção das duas línguas, a LIBRAS e a Língua Portuguesa escrita, o que deve ser incentivado pela escola.
} 
interação limitaram o desenvolvimento da entrevista, e, em função disso, foi feita a opção pela textualização, visando fidedignidade à expressão da aluna.

A textualização é definida, segundo Gattaz (1996), como texto escrito que reproduz uma narrativa, contendo nele o que foi exposto pelo entrevistado; a textualização deve propiciar que o narrador (o entrevistado) reconheça a sua fala no texto. Na textualização, a leitura do texto deve ser fácil e compreensível, o que não ocorre com a transcrição literal, e deve conter em si a atmosfera da entrevista e seu ritmo. As pesquisadoras textualizaram a entrevista e, num segundo encontro, apresentaram para a aluna, que solicitou alterações e/ou complementações Observam-se poucos detalhes da história escolar da aluna, também quanto à cronologia, o que exigiu outras fontes de pesquisa, como o próprio Histórico Escolar. Apresenta-se, na sequência, trecho da textualização que traz os primeiros dados sobre a trajetória da aluna.

"Nasci em 07 de julho de 1993. A surdez foi identificada aos dois anos de idade, e até essa data eu não falava. [...] Em 1997, com quatro anos de idade, frequentei Escola Especial, mas não me recordo das atividades e nem da interação com outras crianças e professores. [...] Cursei o $4^{\circ}$ ano em uma escola de ensino regular, na zona rural do município, e repeti esse ano. Não compreendia o que a professora falava em sala de aula, o que prejudicou meu desenvolvimento e aprendizagem. Na escola regular, as atividades pedagógicas eram iguais às dos demais alunos e não havia nenhuma adaptação ou atendimento especial por parte dos professores que não davam atenção diferenciada. Eu era ajudada pelos colegas de sala. No Fundamental II e Ensino Médio, eu já compreendia melhor os professores e eles perguntavam se precisava de ajuda. [...] Continuei tendo a ajuda dos colegas de sala. Não me lembro se frequentei sala de recurso. Não aprendi LIBRAS. Também não sei sobre quais mudanças nas escolas seriam boas para a inclusão de alunos com deficiência”. (Textualização da aluna)

\subsection{AS ENTREVISTAS COM OS DEMAIS SUJEITOS}

Além da aluna, e visando construir panorama acerca de seu processo de escolarização, foram entrevistados outros sujeitos, a saber: um dos familiares (a mãe), 01 professora dos anos iniciais do Ensino Fundamental, 01 professora dos anos finais do Ensino Fundamental, 01 professor do Ensino Médio e 01 diretor de 
escola, gestor de uma das escolas frequentadas pela aluna ${ }^{6}$. O Quadro 1 apresenta informações referentes aos sujeitos entrevistados.

Quadro 1. Dados dos sujeitos entrevistados

\begin{tabular}{|c|c|c|c|c|}
\hline SUJEITOS & IDADE & FORMAÇÃO & $\begin{array}{c}\text { TEMPO DE } \\
\text { FORMAÇÃO }\end{array}$ & $\begin{array}{c}\text { ÁREA, DISCIPLINA E } \\
\text { NíVEL DE ENSINO } \\
\text { EM QUE ATUA }\end{array}$ \\
\hline MÃE & 45 & $\begin{array}{l}\text { Sem formação } \\
\text { profissional }\end{array}$ & & \\
\hline PFI & 49 & Normal Superior & 27 & $\begin{array}{l}\text { Anos iniciais }\left(3^{\circ} \text { e } 4^{\circ}\right) \\
\text { do Ensino } \\
\text { Fundamental }\end{array}$ \\
\hline PFII & 50 & $\begin{array}{l}\text { Licenciatura em } \\
\text { Letras - Língua } \\
\text { Portuguesa }\end{array}$ & 25 & $\begin{array}{l}9^{\circ} \text {. Ano do Ensino } \\
\text { Fundamental/ Área } \\
\text { Língua Portuguesa }\end{array}$ \\
\hline GESTOR & 32 & $\begin{array}{l}\text { Licenciatura em } \\
\text { Matemática }\end{array}$ & 11 & $\begin{array}{l}\text { Ensino Médio - } \\
\text { Área Física e } \\
\text { Matemática }\end{array}$ \\
\hline Licenciatura em \\
História
\end{tabular}

Fonte: Construção das pesquisadoras, a partir das informações obtidas nas entrevistas (dados de 2013).

Os participantes do estudo têm entre 32 e 50 anos de idade. Os professores (PFI, PFII e PEM) apresentam formação profissional compatível com a função exercida; o gestor indicou, na entrevista, apenas a formação voltada à docência. Em média, possuem 19,5 anos de tempo de formados. O professor que atua no Ensino Médio [PEM] graduou-se há 11 anos, e a professora que esteve com a aluna nos anos iniciais do Ensino Fundamental [PEFI] concluiu o Ensino Superior há 27 anos. Quanto ao tempo de formação, não se observaram diferenças significativas em relação às respostas na entrevista. O mesmo pode ser dito em relação ao nível de ensino em que atuam e função exercida pelos profissionais.

\footnotetext{
${ }^{6}$ Para efeito de organização, os sujeitos serão apresentados pela indicação: mãe, gestor (o diretor de escola); PFI (Professora dos anos iniciais do Ensino Fundamental), PFII (Professora dos anos finais no Ensino Fundamental) e PEM (Professor do Ensino Médio).
} 
A partir da leitura das transcrições das entrevistas, observou-se que, para além das questões iniciais do roteiro de entrevista, os sujeitos entrevistados foram discorrendo sobre outros assuntos, ampliando o foco para outras temáticas. A análise das entrevistas, tendo como direcionamento a Análise de Conteúdo (BARDIN, 1977), fez com que se observassem regularidades nas falas dos sujeitos, agrupadas em temas, identificados na leitura cuidadosa da transcrição das entrevistas. Foram levantados os seguintes temas (organizados em subtemas e conteúdos): interação e colaboração entre os pares de estudantes; comunicação e aprendizagem; atendimento específico da aluna na escola e na sala de aula; o conhecimento do professor acerca da inclusão do aluno com surdez e orientações recebidas pelos profissionais na escola. Esses temas representam a percepção dos entrevistados (professores, gestor, aluna e familiar/mãe) acerca da escolarização dessa aluna.

Uma visão geral dos dados levantados por meio das entrevistas aponta para dificuldades de comunicação com a aluna (o que, segundo os entrevistados, interferiu no seu desempenho pedagógico), ausência da LIBRAS, a Língua Brasileira de Sinais ${ }^{7}$, nas escolas e salas de aula (no período escolar dessa aluna, a saber, de 1997 a 2012), e o desconhecimento dos profissionais entrevistados tanto sobre a surdez como em relação à adequação do trabalho pedagógico. Da mesma forma, a fala dos entrevistados convergiu quanto à ausência da sala de recursos (atualmente, AEE - Atendimento Educacional Especializado) no período de escolarização da aluna, bem como sobre o grande número de alunos nas turmas, também indicado como um aspecto negativo para a inclusão escolar. Os entrevistados afirmaram também sobre a falta de orientações aos professores acerca do trabalho pedagógico a ser realizado.

\footnotetext{
${ }^{7}$ No Brasil, a Lei n. 10.436 (BRASIL, 2002) é um importante marco da inclusão social e escolar das pessoas com surdez, estabelecendo o reconhecimento da LIBRAS, a Língua Brasileira de Sinais, como o meio de comunicação empregado pelas pessoas surdas, assumindo-a como língua, com construção gramatical própria totalmente ligada à cultura construída pela comunidade surda. $\mathrm{O}$ Decreto $\mathrm{n}^{\circ}$ 5.626, de 22 de dezembro de 2005 (BRASIL, 2005), regulamenta a Lei $\mathrm{n}^{\circ} 10.436$, estabelecendo normas para que a LIBRAS seja divulgada e seu uso ampliado para todo o território brasileiro. De acordo com o Artigo $3^{\circ}$ deste Decreto, é necessário construir conhecimento profissional sobre LIBRAS no seu uso em classes comuns e no atendimento educacional especializado, sendo obrigatório o ensino da Língua Brasileira de Sinais também nos cursos de formação profissional, conforme determina o Artigo $6^{\circ}$ deste Decreto.
} 
Em relação às necessidades dessa aluna em sala de aula, tanto os profissionais como a mãe afirmaram que não havia adaptações curriculares de qualquer ordem e nível, nem de conteúdo ou metodológica. Porém, mencionaram o uso de critérios diferenciados na avaliação da aluna, seja na forma como os instrumentos de avaliação eram empregados, por exemplo, com provas e trabalhos em dupla, como afirmou o professor PFI, seja quanto aos próprios critérios de avaliação que eram diferenciados, segundo o professor PEM. Nesse aspecto, os entrevistados falaram sobre a realização de provas em dupla e/ou outras formas de avaliação escrita diferentes dos demais alunos, conforme também o afirmaram PFII e PEM. A fala dos profissionais acerca dessas práticas sugere que as mesmas faltava sistematização e reflexões sobre sua realização; não havia, ainda, segundo os entrevistados, ações planejadas e contextualizadas.

Em relação a um atendimento mais específico para a aluna, os entrevistados disseram que buscavam realizar atendimento individualizado e comentaram sobre dificuldades para sua realização, elencando os motivos. PFI, por exemplo, afirmou que "passava na carteira, mas a aluna não entendia o que ela falava, e vice-versa", o que sugere apenas uma intenção de atender à aluna. Tanto a mãe como o gestor comentaram que este atendimento, voltado às necessidades da aluna, acontecia de forma mais específica nos anos iniciais do Ensino Fundamental; a mãe complementou, dizendo que tentava ajudar em casa na realização das tarefas, mas que a aluna tinha muitas dificuldades. Os professores PFII e PEM, por sua vez, afirmaram que a ausência de atendimento individualizado se devia ao grande número de alunos nas salas e às condições de trabalho nesse contexto.

Dias, Silva e Braun (2009) afirmam que o aluno com surdez aprenderá em qualquer momento da sua vida, desde que suas necessidades específicas sejam atendidas. Para tal, deve haver o emprego de estratégias e recursos de aprendizagem adequados a esse aluno, o que, como afirmaram os professores, não acontecia em suas aulas. Embora a limitação auditiva interfira na construção da linguagem (que se relaciona à função cognitiva), as dificuldades não vêm de uma limitação orgânica ou cognitiva, uma vez que, quando este sujeito faz uso de um código linguístico, passa a interagir, compreender e aprender (SKLIAR, 2009), da mesma forma que outros sujeitos ouvintes quando fazem uso da Língua Portuguesa. 
Reiteramos, portanto, que se faz necessário promover ensino de qualidade, criando espaços e situações de aprendizagem adequadas a esses alunos; para tal, são profícuas as reflexões sobre as práticas pedagógicas desenvolvidas, visando às adequações necessárias.

Dos vários temas levantados nas entrevistas, daremos destaque, na sequência do texto, a um deles, propondo sua discussão. Trata-se da interação e colaboração entre a aluna e seus colegas de turma e das ações dos professores a partir dessa interação, temática que emergiu das entrevistas. A justificativa de sua escolha se refere a sua importância como uma das estratégias empregadas pelos professores na escolarização da aluna. Pela nossa experiência, tal estratégia também se estende à escolarização de outros alunos com necessidades educacionais especiais.

\section{INTERAÇÃO E COLABORAÇÃO ENTRE OS PARES DE ESTUDANTES E OS SABERES DOCENTES}

A apresentação do tema Interação e Colaboração entre os pares de estudante objetiva discutir sobre as ações dos professores a partir da observação da interação da aluna com os colegas e de como essas ações foram sendo adotadas por outros professores e praticamente instituídas como prática comum ao longo da escolarização da aluna. Na análise realizada, o tema foi desdobrado em subtemas e conteúdos, organizados no quadro que segue:

Quadro 2. Interação e colaboração - tema, subtema e sujeitos respondentes.

\begin{tabular}{|c|c|c|}
\hline $\begin{array}{c}\text { TEMA } \\
\text { EMERGENTE }\end{array}$ & SUBTEMAS & SUJEITOS \\
\hline \multirow{2}{*}{$\begin{array}{l}\text { INTERAÇÃO E } \\
\text { COLABORAÇÃO } \\
\text { ENTRE OS PARES } \\
\text { DE ESTUDANTES }\end{array}$} & $\begin{array}{l}\text { 1.Interação e colaboração entre os pares de } \\
\text { alunos, facilitando a aprendizagem. }\end{array}$ & $\begin{array}{l}\text { PFI/ PFII/PEM / } \\
\text { ALUNA /GESTOR }\end{array}$ \\
\hline & $\begin{array}{l}2.0 \text { "bom comportamento", favorecendo a } \\
\text { interação e a aprendizagem. }\end{array}$ & PFI/PFII /GESTOR \\
\hline
\end{tabular}


Para os entrevistados, a interação e a colaboração entre os pares foram citadas como requisitos essenciais para a inclusão escolar no ensino regular da aluna com surdez, caracterizando os meios para facilitar sua aprendizagem (subtema 1). Os sujeitos entrevistados - sobretudo os profissionais que atuaram com a aluna (com reforço dessas informações pela própria aluna e pela sua mãe) afirmaram que, ao longo dos anos, nos diferentes níveis de ensino, a aluna foi sempre orientada a participar de duplas e/ou de pequenos grupos, pois era dessa forma que a aluna realizava suas atividades e produzia, também em relação às avaliações. Tal prática acabou sendo promovida por todos os profissionais e foi empregada em todo o processo de escolarização da aluna, uma vez que a experiência dos docentes, ano após ano, mostrava que essa prática era bem sucedida. Os excertos que seguem apresentam a fala de um dos entrevistados:

"Ela sempre sentava junto com alguns colegas, sempre tinha ao lado os colegas. No começo eu até achava ruim, mais depois que eu percebi que ela tinha deficiência, eu a deixava sentar junto com os outros colegas. Sentava de três, sentava de dois, aí dava para levar normal. Tinha parte da disciplina que ela tinha mais dificuldade; outras partes ela sabia legal. Também ela dependia muito da ajuda das colegas, mas ela fazia os exercícios. Eu não tinha certeza absoluta se ela copiava ou fazia realmente, mas a maioria dos exercícios que eu dava ela fazia". [PEM]

"Eu dava a atividade e tal qual a colega fazia, ela fazia também. E eu aceitava porque eu não sabia trabalhar com ela. Entendeu? Só que era assim, letra maravilhosa, caprichosa, uma belezinha". [PFI]

A própria aluna também afirmou, durante a entrevista, que era ajudada pelos colegas de sala. Isso, conforme a própria aluna, contribuiu tanto na interação social quanto na aprendizagem escolar (dados da entrevista da aluna/Textualização).

Concordamos com tal informação, à luz dos estudos de Vygotsky (1998), que atestam que a interação social pode efetivamente contribuir na aprendizagem quando se converte em trabalho colaborativo. Para este estudioso, o processo de conhecer e aprender se dá nas interações entre sujeitos que são materializadas pelos signos, pelos objetos da cultura e pela linguagem. $O$ conhecimento é construído na interação, tendo por finalidade a internalização do que foi produzido historicamente em dada cultura e em dado grupo social. A aprendizagem, na 
perspectiva vygotskyana, se dá na relação triangular entre sujeito-conhecimentooutro. Sobre este assunto, Bonals (2003) afirma que a interação social na escola favorece as trocas e contribui para a superação de desafios e dificuldades. Os desequilíbrios provocados pelas novas aprendizagens são minimizados e facilmente apreendidos quando o sujeito está em interação com outros. Segundo esse autor, os professores deveriam usar a interação social entre os escolares como ferramenta pedagógica importante e propiciadora de desenvolvimento.

Embora consideremos a contribuição da interação e da colaboração entre os pares no desempenho escolar, no caso em estudo, se refletirmos do ponto de vista dos objetivos instrucionais e das estratégias de ensino, não houve, segundo os próprios entrevistados, reflexões sobre possíveis resultados da prática do trabalho em duplas e em grupo na aprendizagem da aluna. Essa prática foi estimulada pelos professores inicialmente como uma tentativa, e a percepção dos seus resultados constituíram-na como uma prática de sala de aula, adotada pelos profissionais ao longo de todo o processo de escolarização da aluna. Essa prática foi mantida pela percepção (informal e assistemática) de que essa forma de trabalhar, com a colaboração de outros alunos, levava a processo e produção final diferentes do trabalho individual, de quando a aluna não contava com a colaboração de colegas. As falas dos profissionais nas entrevistas sugerem que essa prática não foi incorporada como trabalho pedagógico, uma vez que, nas aulas de alguns professores, a interação e a colaboração eram espontâneas, ficando a cargo dos próprios alunos. Tal fato também indica insuficiência da mediação do professor nas atividades em duplas e grupos, condição citada por Vygotsky (1998) como fundamental aos processos de aprendizagem e interação. Deve-se ainda refletir que no caso da aluna surda inserida no contexto essencialmente verbal da sala de aula, embora a interação com os colegas ouvintes promovesse a mediação da aluna com esse contexto, a ausência de Libras também precisa ser considerada na qualidade da interação estabelecida, sobretudo quanto à compreensão pela aluna dos conceitos verbais em discurso.

Ainda quanto à temática da interação e colaboração entre os estudantes, a fala dos entrevistados, conforme excertos a seguir, sugere que 0 bom 
comportamento da aluna compensava suas limitações e dificuldades e também facilitava a interação e a aprendizagem (subtema 2).

“Ela não dava trabalho e interagia bem". [PFI]

"Era uma aluna que relacionava super bem, sem nenhum problema”. [PFII]

"Olha, acho o que facilitou primeiramente foi a questão da socialização dela. Ela sempre foi bem relacionada, sempre se deu muito bem com os amigos, com os colegas, nunca tivemos nenhum fato assim relevante de desentendimento; pelo contrário, ela era sempre carismática, simpática com os colegas, então acho que já é o primeiro fator". [gestor]

Afirmações como "ela não dava trabalho", "sem nenhum problema" e "era sempre carismática", dos trechos anteriores, parecem evidenciar que a aluna com surdez ficava escondida atrás desse bom comportamento, que também escondia a própria deficiência. Era como se o fato de ela ficar quieta compensasse suas dificuldades e, ainda, a fizesse aprender. Ao contrário disso, a inclusão escolar deve objetivar a aprendizagem e participação ativa do aluno com necessidades educacionais especiais em sala de aula e na escola. Disciplina e bom comportamento são aspectos que, em absoluto, podem ainda hoje fazer parte das considerações acerca da aprendizagem escolar de qualquer aluno, porém os dados sugerem que tal relação permanece.

Uma vez que concebemos a prática docente na relação com saberes que subjazem a ela, construídos desde a formação inicial, em contato com conhecimentos socialmente construídos e no exercício docente, tendo em vista o que se apresentou neste item questiona-se: que saberes estavam na base das ações desses professores? O que sabiam (incluindo nesse saber, um não saber) que os levava a, por exemplo, situar a aluna em duplas e em pequenos grupos sem a mediação do professor? Em suma, que saberes docentes - percebidos pela família e vividos pela aluna - alicerçavam suas ações? Em função da ideia de que os saberes são construídos e reconstruídos em sua relação com as ações docentes (TARDIF, 2007), apresentam-se, na sequência dessa discussão, reflexões sobre os saberes dos entrevistados acerca da inclusão escolar. O estabelecimento de relações entre esses dois aspectos - a interação e a colaboração entre os pares e 
os saberes dos professores acerca da aprendizagem da aluna - pode contribuir na elucidação dos resultados da pesquisa e nas reflexões mais gerais sobre a inclusão escolar.

\section{SABERES E PRÁtICAS NO PROCESSO DE ESCOLARIZAÇÃO DA ALUNA COM SURDEZ}

É intrínseca a relação entre os saberes dos docentes e seu fazer: se sabem que seus alunos não aprendem, por exemplo, os professores podem agir de forma diferente do que, ao contrário, podem promover se sabem que eles podem aprender. Nesse sentido, os saberes dos professores sobre a inclusão escolar de alunos com necessidades educacionais especiais, sobretudo saberes que afirmam a ineficiência e insucesso da inclusão, estão, provavelmente, na base de ações docentes voltadas a manter o aluno em atividade (qualquer atividade) e/ou em grupo, condições que não representam a inclusão escolar em sua totalidade e complexidade, o que, em muitas situações, também caracterizou o trabalho com essa aluna.

A análise das entrevistas dos sujeitos que participaram da pesquisa indica, na emergência dos seus saberes, os sentidos que afirmam que a inclusão escolar ainda não se efetivou do ponto de vista da construção efetiva e é a partir dessa afirmação, desse lugar social e discursivo, que possivelmente age este sujeito, seja professor, familiar ou até mesmo a aluna. Para a professora que atuou com a aluna nos anos iniciais do Ensino Fundamental, por exemplo, as dificuldades da/na inclusão escolar estão relacionadas às condições de trabalho, em específico à ausência de trabalho de equipe e de orientações para os professores.

"Ninguém nunca perguntava nada e isso acontece até hoje em dia. A inclusão é meio que no papel ainda, viu? É muita dificuldade, porque não adianta mesmo, tem que trabalhar separado. É complicado, viu?" [PFI]

Afirmações como "a inclusão é meio que no papel ainda" e "é complicado" (do excerto anterior) indicam a percepção da professora acerca da inclusão escolar e também revelam seu saber, a partir do qual a professora se posiciona, responde e atua. 
Para outros profissionais, como para o gestor, a inclusão escolar do aluno com necessidades educacionais especiais deve ser pensada no contexto da educação em geral, na reflexão mais ampla sobre a construção de educação de qualidade para todos.

"Então, sobre a questão da inclusão, penso que a primeira inclusão que tem que acontecer é a da pauta da educação como prioridade do poder público. Sem pensar na escola como algo prioritário, o que ainda, infelizmente, está em vias de acontecer, não se pode pensar na inclusão.

Você fala na questão da acessibilidade mas ainda é mais fácil. Você identificou, ainda é uma coisa palpável. A escola tem cadeirante, nós precisamos de rampa. Nós não temos rampa, mas, se amanhã tivermos uma situação assim, é rápido, isso resolve. Mas na questão metodológica e de recursos, não é só a questão da inclusão daqueles com necessidades especiais, mas do próprio aluno sem necessidade. A escola não está conseguindo incluir e é difícil, então, assim". [gestor]

É também recorrente, como afirmou o gestor, o discurso de que as dificuldades para a inclusão escolar de alunos com necessidades educacionais especiais têm relação com a baixa qualidade da educação. Embora seja algo que precisa ser considerado, essas afirmações ampliam as barreiras que são colocadas para a inclusão escolar. A escolarização no ensino regular de alunos com necessidades educacionais especiais, um direito, não poderá esperar que todos os problemas educacionais sejam resolvidos. Será preciso esforço e trabalho coletivo para sua superação e, também, a plena acolhida desse projeto.

Outro discurso comum e que também emergiu nas entrevistas é o de que os alunos estão na escola como forma de se socializarem. A professora afirmou:

"Sim, porque você estava muito próximo, então chegava até a carteira conversava com ela, se aproximava dela, interagia como um aluno que estava ali e necessitava de atenção, do seu carinho. Independente de aprender ou não, de abstrair ou não o rol de conhecimentos, a inclusão é mais a questão social, a inclusão social mesmo do aluno se sentir amado, se sentir incluído também no meio escolar". [PFII]

A fala desta professora sugere a inclusão escolar relacionada ao fato de o aluno estar no ensino regular e participando de atividades comuns a outros alunos, 
independente de seu desempenho e aprendizado. Nesse caso, a interação social e a participação são aspectos valorizados em detrimento da aprendizagem.

Como já se afirmou, entendemos que as ações dos professores se originam dos seus saberes (TARDIF, 2007) acerca de, nesse caso, o lugar dado à inclusão escolar pelos profissionais da educação e sociedade em geral. Se os sujeitos envolvidos nesse processo afirmam a inclusão como "no papel" e questionam as condições de trabalho docente, isso explica, em certa medida, as ações que realizam, o que suas falas durante a entrevista revelam. Porém, se, por um lado, as falas dos profissionais podem indicar dúvidas e práticas que mostram certo espontaneísmo; por outro lado, a necessidade de se construírem práticas pedagógicas que realmente atendam ao aluno com necessidades educacionais especiais têm levado os profissionais a se mobilizarem, buscando por soluções para as dificuldades encontradas na construtiva confrontação entre o que sabem e o novo que os interpela e provoca.

\section{CONSIDERAÇÕES FINAIS}

A inclusão escolar de alunos com necessidades educacionais especiais em escolas do ensino regular é ainda uma construção e, tendo em perspectiva a sua importância, buscou-se investigar o processo de escolarização, na Educação Básica, de uma aluna com surdez. Em relação ao trabalho pedagógico desenvolvido, a pesquisa indicou a ausência de conhecimentos necessários aos profissionais, como o da LIBRAS, porém indicou também que os mesmos construíram práticas voltadas a sua aprendizagem. Algumas dessas práticas, por exemplo a realização de atividades em dupla e em pequenos grupos, precisam de análise e reflexão aprofundada para que assumam um caráter pedagógico. A reflexão sobre essas práticas, no movimento de construção da inclusão escolar de alunos com necessidades educacionais especiais, pode promover mudanças e adequações necessárias, bem como outras formas de agir dos docentes a partir do (re)conhecimento dos fins da educação escolar e da inclusão escolar. Ressaltamos, 
nesse processo, a importância de que o próprio aluno e seus familiares sejam ouvidos. Na pesquisa, o relato da aluna e de sua mãe apontaram para a ausência de recursos e de atendimentos específicos para essa aluna, bem como para a desinformação de alguns professores acerca da adequação do trabalho pedagógico.

Outro aspecto discutido no texto refere-se à relação entre o fazer e o saber dos professores junto a alunos com necessidades educacionais especiais. Os dados levantados na pesquisa sugerem relação entre a fala dos professores, quando, por exemplo, indicam que o objetivo da inclusão escolar é a socialização, com algumas de suas ações e justificativas como a afirmativa de que seu bom "comportamento" seria fator de aprendizagem, compensando as suas limitações.

Nesse sentido, reafirmamos a necessidade da ressignificação daquilo que julgamos saber, tendo em vista a importância de que possamos, professores, (re)construir novas e outras formas de ensinar e aprender. No bojo das considerações a que chegamos com os resultados dessa pesquisa, apontamos também para a formação docente que deve ser pensada como processo contínuo, cuja origem é a formação inicial, mas se estende ao exercício docente e, como vimos afirmando, às necessárias reflexões sobre a prática profissional e o cotidiano escolar.

\section{CARLA HELENA FERNANDES}

Doutora em Educação. Professora do Mestrado em Educação da Universidade do Vale do Sapucaí (UNIVÁS), Pouso Alegre - MG.

\section{ALINE REZENDE CAMPOS}

Pedagoga pela Universidade do Vale do Sapucaí (UNIVÁS), Pouso Alegre - MG, Professora da Educação Infantil.

\section{REFERÊNCIAS}

BARDIN, L. Análise de conteúdo. Lisboa: Edições 70, 1977, 280 p.

BONALS, J. O trabalho em pequenos grupos na sala de aula. Porto Alegre:

ARTMED, 2003, $180 \mathrm{p}$. 
BOGDAN, R.; BIKLEN, S. Investigação qualitativa em Educação. Porto: Porto Editora, 1994, $336 \mathrm{p}$.

BRASIL. Lei n. 10.436, de 24 de abril de 2002. Dispõe sobre a Língua Brasileira de Sinais e dá outras providências. Diário Oficial da União de 25 de abril de 2002. Disponível em: <http://www.planalto.gov.br/ccivil_03/leis/2002/L10436.htm>. Acesso em: outubro de 2013.

. Decreto n. 5.626, de 22 de dezembro de 2005. Regulamenta a Lei $\mathrm{n}^{\circ}$ 10.436, de 24 de abril de 2002, que dispõe sobre a Língua Brasileira de Sinais LIBRAS. Diário Oficial da União de 23 de dezembro de 2005. Disponível em: <http://www.planalto.gov.br/ccivil_03/_ato2004-2006/2005)decreto/d5626.htm>. Acesso em: outubro de 2013.

DIAS, V. L.; SILVA, V. A.; BRAUN, P. A inclusão do aluno com deficiência auditiva na classe regular: reflexões sobre a prática pedagógica. In: GLAT, R. (org.). Educação inclusiva: cultura e cotidiano escolar. Rio de Janeiro: 7Letras, 2009. p. 97115.

FRANCO, M. A.S. Práticas pedagógicas nas múltiplas redes educativas. In: LIBÂNEO, J.C; Alves, N. (orgs.) Temas de Pedagogia. Diálogos entre Didática e Currículo. São Paulo: Cortez, 2012. p. 169-188.

GATTAZ, A. Lapidando a fala bruta: a textualização em História Oral. In: MEIHY, J. C. S. B. (org.). (Re)definindo a História Oral no Brasil. São Paulo: Ed. Xamã, 1996. p. $135-40$.

LÜDKE, M.; ANDRÉ, M. E. D. A. Pesquisa em Educação: abordagem qualitativa. São Paulo: EPU, 1986, 99 p.

MINISTÉRIO DA EDUCAÇÃO. Secretaria de Educação Especial.Política Nacional de Educação Especial na Perspectiva da Educação Inclusiva. Brasília: MEC/SEESP, 2008. Disponível em:<http://portal.mec.gov.br/seesp/arquivos/pdf/politica.pdf>. Acesso em 10 out. 2013.

SKLIAR, C. Atualidade da educação bilíngue para surdos. Interfaces entre Pedagogia e Linguística. 3. ed. Porto Alegre: Mediação, 2009, 272 p.

TARDIF, M. Saberes docentes e formação profissional. 8. ed. Petrópolis: Vozes, 2007, 328 p.

TRIVIÑOS, A. N. S. Introdução à pesquisa em ciências sociais. A pesquisa qualitativa em educação. São Paulo: Atlas, 1987, 176 p.

UNESCO. Declaração de Salamanca e Enquadramento da ação na área das necessidades especiais. Conferencia Mundial sobre Educação para as necessidades especiais: acesso e qualidade. UNESCO: Salamanca, 1994. Disponível em: <http://unesdoc.unesco.org/images/0013/001393/139394por.pdf> 


\section{Atos de Pesquisa em Educação - ISSN 1809-0354}

Blumenau, v. 9, n.3, p.699-719, set./dez. 2014

DOI: http://dx.doi.org/10.7867/1809-0354.2014v9n3p699-719

Acesso em: 10 out. 2013.

VYGOTSKY, L. S. A formação social da mente. 6. ed. São Paulo: Martins Fontes, 1998, 220 p.

YIN, R.K. Estudo de caso: Planejamento e método. 3. ed. Porto Alegre: Bookman, 2005, 212 p. 